\title{
Biology of Triatoma pallidipennis Stal 1945 (Hemiptera: Reduviidae:Triatominae) under Laboratory Conditions
}

\author{
José Alejandro Martínez-Ibarra ${ }^{+}$, Gala Katthain-Duchateau
}

\author{
Laboratorio de Microbiología, Centro Universitario de Ciencias de la Salud, Universidad de Guadalajara, \\ Apartado Postal 119-4 44100, Guadalajara, Jalisco, México
}

Aspects related to hatching, life time, mortality, feeding behaviour and fecundity for each stage of Triatoma pallidipennis life-cycle were evaluated. The hatching rate observed for 200 eggs was $60 \%$ and the average time of hatching was 18 days. Eighty nymphs $(N)(40 \%)$ completed the cycle and the average time from NI to adult was $168.7 \pm 11.7$ days. The average span in days for each stage was 18.0 for NI, 18.5 for NII, 30.0 for NIII, 35.7 for NIV and 50.1 for NV. The number of bloodmeals at each nymphal stage varied from 1 to 5. The mortality rate was 9.17 for NI, 5.5 for NII, 6.8 for NIII 4.17 for NIV and 13.04 for NV nymphs. The average number of eggs laid per female in a 9-month period was 498.6. The survival rates of adults were $357 \pm 217.9$ and $262.53 \pm 167.7$ for males and females respectively.

Key words: Triatoma pallidipennis - biology - ethology - laboratory conditions

Triatoma pallidipennis Stal, is one of the most important vectors of Chagas disease in Mexico, occurring in houses and chicken coops in villages of central Mexico (Lent \& Wygodzinsky 1979, Zárate \& Zárate 1985, Beltrán \& Carcavallo 1985, VelascoCastrejón 1991, Magallón-Gastélum et al. 1998, Martínez-Ibarra et al. 1998, 1999). The biology and behavior of this species have been poorly studied (Maifrino et al. 1989, Martínez-Ibarra et al. 1992, Mena-Segura et al. 1994), in spite of its domiciliarity, frequent contact with man as a blood meal source and high infection rates with Trypanosoma cruzi (Velasco-Castrejón 1991, Magallón-Gastélum et al. 1998, Martínez-Ibarra et al. 1998, 1999, Bautista et al. 1999).

As a part of a larger study on the ecology of $T$. pallidipennis, studies of the biology of $T$. pallidipennis under experimental conditions are described.

\section{MATERIALS AND METHODS}

A laboratory colony established in 1988 from specimens captured in Zacoalco de Torres, Jalisco, was used. The colony was mantained at $25 \pm 4^{\circ} \mathrm{C}$ and $60 \pm 5 \%$ relative humidity (rh) and fed every three days on immobilized leghorn hens.

\footnotetext{
${ }^{+}$Corresponding author. Present address: Colegio de Postgraduados, Instituto de Fitosanidad, km. 35.5, Carr. México-Texcoco, 56230 Montecillo, Estado de México, México. Fax: +52-595-20261.

E-mail: aibarra@colpos.colpos.mx

Received 23 March 1999

Accepted 11 August 1999
}

Eggs were grouped by date of oviposition to initiate a cohort of 200 eggs. After eclosion, firstinstar nymphs were separated individually into plastic containers ( $10.5 \mathrm{~cm}$ diameter x $20.5 \mathrm{~cm}$ heigh), with an upcenter support of absorbent cardboard. Three days after eclosion, the nymphs were individually offered a feed during a $1 \mathrm{hr}$ period until the first blood meal, after that they were offered feed every third day. The bugs were maintained in a dark incubator at $27 \pm 2^{\circ} \mathrm{C}$ and $60 \pm 5 \% \mathrm{rh}$, and were checked daily for ecdysis or death.

From the insects that completed development to the adult stage, 15 adult couples were placed in individual containers $(10.5 \mathrm{~cm}$ diameter x $20.5 \mathrm{~cm}$ height) and maintained as previously described to determine adult survival rates and oviposition patterns.

\section{RESULTS}

Egg eclosion rate was $60 \%$ with an average incubation period of 18 days (range 16-27 days). Eighty nymphs completed development to the adult stage (45 males and 25 females) (Table I), taking an average of 2.8 blood meals per nymphal stage (range 1-5) (Table II). The average egg-to-adult development time was 168.7 days (range 131-199) (Table I). The adult survival levels ranged from 27 to 620 days for males (mean 357 \pm 217.86 ) and from 34 to 570 days for females (mean $262.53 \pm 167.71$ ). The average number of eggs laid per female was 498.67 (range 408552).

A partial life table analysis, following the methods of Southwood (1978), indicates a net reproductive rate (Ro) of 145.4 times per generation under these conditions, with an instantaneous daily reproductive rate (r) of 0.062 (Table III). 
TABLE I

Egg to adult development cycle of Triatoma pallidipennis fed every three days on hens

\begin{tabular}{lrrrr}
\hline \multirow{2}{*}{ Stage } & & \multicolumn{3}{c}{ Number duration in days } \\
\cline { 3 - 5 } & & Min. & Max. & Mean \pm SD \\
\hline Egg-NI & 120 & 16 & 27 & $18.0 \pm 2.09$ \\
NI-NII & 109 & 9 & 25 & $18.0 \pm 1.80$ \\
NII-NIII & 103 & 12 & 27 & $18.5 \pm 2.69$ \\
NIII-NIV & 96 & 18 & 38 & $30.0 \pm 3.95$ \\
NIV-NV & 92 & 33 & 50 & $35.7 \pm 3.80$ \\
NV-AD & 80 & 36 & 59 & $50.1 \pm 4.18$ \\
\hline Total & 80 & 131 & 199 & $168 \pm 11.71$
\end{tabular}

TABLE II

Number of blood meals and stage mortality for Triatoma pallidipennis

\begin{tabular}{lccccc}
\hline \multirow{2}{*}{$\begin{array}{c}\text { Stage } \\
\text { Number of } \\
\text { nymphs }\end{array}$} & \multicolumn{3}{c}{ Number of bloodmeals } & $\%$ \\
\cline { 3 - 5 } & & Min. & Max. & Mean \pm SD & \\
\hline I & 120 & 1 & 3 & $1.99 \pm .054$ & 9.17 \\
II & 109 & 2 & 3 & $2.15 \pm 0.35$ & 5.50 \\
III & 103 & 3 & 5 & $3.24 \pm 0.80$ & 6.80 \\
IV & 96 & 2 & 3 & $2.52 \pm 0.50$ & 4.17 \\
V & 92 & 3 & 4 & $3.43 \pm 0.50$ & 13.04 \\
\hline Total & 80 & - & - & - & $(38.68)$ \\
\hline
\end{tabular}

TABLE III

Partial stage specific life table for Triatoma pallidipennis (notation following Southwood 1978)

\begin{tabular}{ccr}
\hline Stage & Lx & Dx \\
\hline Egg & 200 & 80 \\
I & 120 & 11 \\
II & 109 & 6 \\
III & 103 & 7 \\
IV & 96 & 4 \\
V & 92 & 12 \\
Adult & 80 & 80 \\
\hline
\end{tabular}

$$
\begin{aligned}
& \text { Ro }=\frac{\begin{array}{c}
\text { Number of females produced by cohort } \\
\mathrm{x} \text { mean eggs laid per female }
\end{array}}{\text { Number of eggs beggining a cohort }}=145.4 \\
& \mathrm{r}=\log (\mathrm{Ro}) / \text { egg-to-egg generation time }=0.062 \\
& \mathrm{Lx}=\text { number entering stage } \mathrm{x} ; \\
& \mathrm{Dx}=\text { number dying in stage } \mathrm{x} .
\end{aligned}
$$

\section{DISCUSSION}

The development cycle of a triatomine varies according to species, the specific environmental conditions and it is greatly influenced by the availability of blood sources (Schofield 1985).

Extrapolations from laboratory data to natural populations are relatively easy in domiciliary triatomines, because in nature all life stages occur in a single type of environment and have similar biological requirements. The most important biological factors that are necessary to understand the populations dynamics of any species include: development time and mortality of immature stages; number of female progeny emerged, onset of sexual maturity, fertility and fecundity, mating habits; longevity, and rate of oviposition with respect to feeding frequency (Perlowagora-Szumlewicz 1953). While biological data are available for many species, comparisons among studies are difficult due to wide differences in experimental design, especially with respect to the temperature, humidity (often uncontrolled), feeding frequency, blood meal sources, number of specimens and stage of species studied, density of insects per container, and frequency of observations (Zárate 1983).

The average development time of $T$. pallidipennis in this study (168.7 \pm 11.71 days) was shorter than the development time for this species in a previous study (411days) since it was carried out under different feeding frequency (10-12 days) but similar laboratory conditions and source of blood (hens) (Mena-Segura et al. 1994). This is supported by a previous study with other Triatoma species (Galavíz-Silva et al. 1991) where the most frequent feeding the shortest development time. Also, the average development time in our study was similar to other Triatoma species. Zeledón et al. (1970a) observed an average development time of 240 days (range 180-336 days) for $T$. dimidiata feeding fortnightly on rabbits and maintained at $26.5 \pm 0.5^{\circ} \mathrm{C}$ and $50 \pm 5 \%$ rh. Rabinovich (1972) found an average development time of 141 days for T. infestans fed weekly on hens and maintained at $26 \pm 1^{\circ} \mathrm{C}$ and $60 \pm 10 \% \mathrm{rh}$. Zárate (1983) reported an average development time of 143.7 days for females and 205.3 for males of $T$. barberi fed every 4.2 days on rabbits and maintained at $27^{\circ} \mathrm{C}$ and $60 \pm 10 \%$ rh. Ehrenfeld et al. (1998) reported a range of 285-372 of development time for Mepraia (= Triatoma) spinolai fed weekly on chickens and maintained at $28^{\circ} \mathrm{C}$ and $70 \% \mathrm{rh}$.

Egg hatching rates in Triatoma species also vary. They are generally above $80 \%$ (Zeledón et al. 1970b, Rabinovich 1972, Zárate 1983, Braga 1998), although lower average hatch rates of $65.9 \%$ have been recorded in colonies of $T$. gerstaeckeri examined under controlled conditions (Galaviz et al. 1991). Egg hatching rate in $T$. pallidipennis in this study $(60 \%)$ was similar to that reported by Mena-Segura et al. (1994) in the same species (61.9\%), since laboratory conditions were similar.

Mortality showed an irregular pattern. The lowest mortality rate was in the molt from fourth to fifth stage, different to reported data by Mena-Segura et al. (1994) for T. pallidipennis, where mortality was 
zero in the three youngest nymphal stages; meanwhile the highest was between the fifth to adult, similar to results reported by the same author. In the youngest nymphs, mortality appeared to be due mainly to an incapacity to feed, since dead bugs were generally without significant intestinal content. In contrast, mortality in the older nymphs occurred mainly during their moulting. On average, approximately $75 \%$ of stages II-V required two and a half meals in order to molt to the next stage.

The mean adult survival levels $(357 \pm 17.86)$ days for males and $(262.53 \pm 167.71)$ for females were longer than those reported by Mena-Segura et al. (1994) (182 for males and 225 for females) since feeding frequency was lower than used in our study.

The typical development time and high reproductive rate may reflect how closely the experimental conditions were controlled to match the optimal conditions for this species. The average net reproduction rate (Ro) for T. pallidipennis was 145.4, considerably higher than those calculated for $T$. barberi reared under very similar controlled conditions $($ Ro = 89.1) (Zárate 1983), for T. maculata reared under similar controlled conditions $\quad(\mathrm{Ro}=$ 80.5) (Feliciangeli \& Rabinovich 1998) and that calculated for $T$. infestans reared under different controlled conditions $(\mathrm{Ro}=25)$ (Rabinovich 1972).

\section{ACKNOWLEDGEMENTS}

To Dr Nina Bárcenas and Dr Jesus Romero for help on the revision of the manuscript.

\section{REFERENCES}

Bautista NL, García de la Torre GS, De Haro I, Salazar PM 1999. Importance of Triatoma pallidipennis (Hemiptera: Reduviidae) as a vector of Trypanosoma cruzi (Kinetoplastida: Trypanosomatidae) in the state of Morelos, Mexico and possible ecotopes. J Med Entomol 36: 233-235.

Beltrán L, Carcavallo RU 1985. México, p. 437-442 In RU Carcavallo, E Rabinovich \& J Tonn (eds), Factores Biológicos y Ecológicos en la Enfermedad de Chagas, Ministerio de Salud y Acción Social, República Argentina.

Braga MV, Pinto ZT, Lima MM 1998. Life cycle and reproductive patterns of Triatoma rubrofasciata (De Geer, 1773) (Hemiptera: Reduviidae), under laboratory conditions. Mem Inst Oswaldo Cruz 93: 539542.

Ehrenfeld MJ, Canals M, Cattan PE 1998. Population parameters of Triatoma spinolai (Heteroptera: Reduviidae) under different environmental conditions and densities. J Med Entomol 35: 740-744.

Feliciangeli MD, Rabinovich J 1985. Vital statistics of Triatominae (Hemiptera: Reduviidae) under laboratory conditions. II Triatoma maculata. J Med Entomol 22: $43-48$.

Galaviz-Silva L, Jiménez-Guzmán F, Fernández-Salas I, Molina-Garza ZJ, Martínez-Ibarra JA 1991. Datos biológicos de Triatoma gerstaeckeri Stal bajo condiciones de laboratorio. Pub Biol FCB/UANL 5: 81-87.

Lent H, Wygodzinsky P 1979. Revision of the Triatominae (Hemiptera:Reduviidae) and their significance as vectors of Chagas disease. Bull Am Mus Nat Hist 163: 123-520.

Magallón-Gastélum E, Magdaleno-Peñaloza NC, Katthain-Duchateau G, Trujillo-Contreras F, Lozano-Kasten FJ, Hernández-Gutiérrez R 1998. Distribución de los vectores de la enfermedad de Chagas (Hemiptera: Reduviidae: Triatominae), en el estado de Jalisco, México. Rev Biomed 9: 151-157.

Maifrino LBM, Campos APS, Montanheiro MR, Boanain E 1989. Contribuation to the knowledge on the biology of Triatoma pallidipennis under laboratory conditions (Hemiptera-Reduviidae-Triatominae). Mem Inst Oswaldo Cruz 84: 113.

Martínez-Ibarra JA, Alejandre-Aguilar R, BárcenasOrtega NM, Nogueda-Torres B, Magallón-Gastélum E, Rodríguez-Sánchez LM 1999. Infestation rates for the triatomines in the west coast of Mexico, $p$. 37. In Mem LXV Ann Meeting Am Mosq Cont Assoc, St. Louis, Mo, USA.

Martínez-Ibarra JA, Katthain-Duchateau G, GalavizSilva L 1992. Estudio sobre los hábitos biológicos de Triatoma pallidipennis (Stal) bajo condiciones de laboratorio. Pub Biol FCB/UANL 6: 44-48.

Martínez-Ibarra JA, Magallón-Gastélum E, RodríguezLópez MH, Arredondo-Jiménez JI, DomínguezSibaja L 1998. Breve actualización de la situación de los triatominos (Hemiptera: Reduviidae) vectores de la enfermedad de Chagas en algunas localidades de Chiapas, Jalisco y Nayarit, p. 337-341. In Mem XXXIII Cong Nal Entomol, Acapulco, México.

Mena-Segura C, Carcavallo RU, Galíndez-Girón I, Canale D 1994. Ciclo de vida de Triatoma pallidipennis (Stal, 1872) (I) (Hemiptera: Reduviidae: Triatominae). Entomol Vect 1: 33-38

Perlowagora-Szumlewicz A 1953. Ciclo evolutivo do Triatoma infestans em condições de laboratorio. Rev Brasil Malar Trop 5: 35-47.

Rabinovich J 1972. Vital statistics of triatominae (Hemiptera: Reduviidae) under laboratory conditions. I Triatoma infestans Klug. J Med Entomol 9: 351-370.

Schofield CJ 1985. Population dynamics and control of Triatoma infestans. Ann Soc Belge de Méd Trop 65 (Suppl. 1): 149-164.

Southwood TRE. 1978. Ecological Methods, 2nd ed., Chapman \& Hall, London, 524 pp.

Velasco-Castrejón O 1991. La Enfermedad de Chagas, Publicación Técnica del Instituto de Diagnóstico y Referencia Epidemiológica (INDRE), México, 56pp.

Zárate LG 1983. The biology and behavior of Triatoma barberi (Hemiptera: Reduvidae) in Mexico. III. Completion of the life cycle adult longevity, and egg production under optimal feeding conditions. $\mathrm{J}$ Med Entomol 20: 485-497.

Zárate LG, Zárate RJ. 1985. A checklist of the triatominae (Hemiptera: Reduviidae) of Mexico. Intern J Entomol 27: 102-127. 
840 Biology of Triatoma pallidipennis - José Alejandro Martinez-lbarra et al.

Zeledón R, Guardia VM, Zúñiga A, Swartzwelder JC 1970a. Biology and ethology of Triatoma dimidiata (Latreille, 1811). I Life cycle, amount of blood ingested, resistance to starvation, and size of adults. $J$ Med Entomol 7: 313-319.
Zeledón R, Guardia VM, Zúñiga A, Swartzwelder JC 1970b. Biology and ethology of Triatoma dimidiata (Latreille, 1811). II Life span of adults and fecundity and fertility of females. J Med Entomol 7: 462-469. 